\section{Commentary: Reoperative cardiac surgery: The importance of surgeon judgment}

\author{
James A. Brown, MA, ${ }^{a}$ and Ibrahim Sultan, MD $^{\mathrm{a}, \mathrm{b}}$
}

Reoperative cardiac surgery has been associated with adverse perioperative outcomes. ${ }^{1-3}$ While reoperative patients typically present with increasingly complex cardiac pathologies as well as an increased burden of clinical comorbidities, redo cardiac surgery also carries inherent risk. In the setting of adhesive disease that develops after previous open-heart surgery, resternotomy increases the potential for injuring the ascending aorta, right ventricle, or previous bypass grafts. Strategies to mitigate these risks have been numerous, including routine computed tomography for preoperative riskstratification, alternative cannulation strategies for establishing cardiopulmonary bypass (CPB), and minimized dissection of cardiac and mediastinal structures. ${ }^{4-8}$ Peripheral initiation of $\mathrm{CPB}$ to decompress the heart before resternotomy has been employed by many surgeons with the goal to reduce injury on re-entry and mitigate catastrophic hemorrhage. However, peripheral cannulation remains controversial because of its association with longer duration of $\mathrm{CPB}$, excessive perioperative bleeding, and potentially increased incidence of stroke. Thus, if and when to use peripheral cannulation to initiate CPB before resternotomy remains controversial.

\footnotetext{
From the ${ }^{\text {aDivision }}$ of Cardiac Surgery, Department of Cardiothoracic Surgery, University of Pittsburgh; and ${ }^{\mathrm{b}} \mathrm{Heart}$ and Vascular Institute, University of Pittsburgh Medical Center, Pittsburgh, Pa.

Disclosures: I.S. receives institutional research support from Medtronic and AtriCure and serves as a consultant for Medtronic Vascular. These conflicts are unrelated to this article. J.A.B. reported no conflicts of interest.

The Journal policy requires editors and reviewers to disclose conflicts of interest and to decline handling or reviewing manuscripts for which they may have a conflict of interest. The editors and reviewers of this article have no conflicts of interest.

Received for publication Jan 10, 2021; revisions received Jan 10, 2021; accepted for publication Jan 11, 2021; available ahead of print Jan 20, 2021.

Address for reprints: Ibrahim Sultan, MD, Division of Cardiac Surgery, Department of Cardiothoracic Surgery University of Pittsburgh UPMC Center for Thoracic Aortic Disease, Heart and Vascular Institute University of Pittsburgh Medical Center, 5200 Centre Ave, Suite 715, Pittsburgh, PA 15232 (E-mail: sultani@upmc. edu).

J Thorac Cardiovasc Surg 2022;164:1769-71

$0022-5223 / \$ 36.00$

Copyright (c) 2021 by The American Association for Thoracic Surgery

https://doi.org/10.1016/j.jtcvs.2021.01.017
}

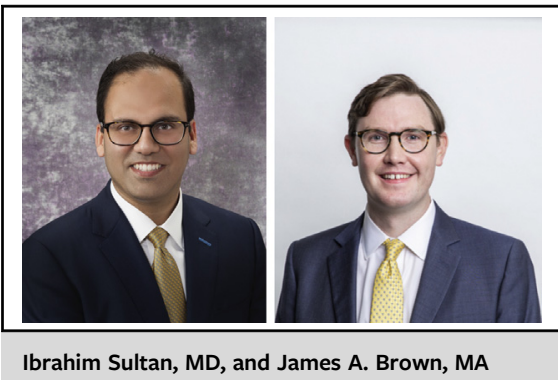

CENTRAL MESSAGE

After stratifying anatomic risk for re-entry injury during reoperative cardiac surgery, there may be clinical equipoise for initiating cardiopulmonary bypass either before or after resternotomy.

In this issue of the Journal, Kindzelski and colleagues ${ }^{9}$ present outcomes of their risk-stratifying approach to reoperative cardiac surgery. While there is a wealth of granular data in this study to ponder, it is critical to dwell on the study's design to understand its implications. In an observational study of 7640 patients undergoing reoperative cardiac surgery from 2008 to 2017 at the Cleveland Clinic, the authors primarily sought to assess the impact of "imageguided stratification of sternal re-entry risk and [the] utility of peripheral cannulation and initiation of CPB before resternotomy." After excluding patients requiring emergent initiation of peripheral CPB because of hemodynamic instability or bleeding, they classified all patients according to preoperative anatomic risk as well as timing of CPB. Radiographic evidence of adherence of previous bypass grafts, the ascending aorta, or an aortic pseudoaneurysm to the undersurface of the sternum defined the high anatomic risk cohort, while timing of CPB was dichotomized as "early" (if before resternotomy) and "late" (if after resternotomy). For all patients, propensity scores were generated via logistic regression to predict the probability of receiving early CPB. Importantly, the high and low anatomic risk cohorts were analyzed separately. Within each anatomic risk category, the patients were propensity weighted and compared by timing of $\mathrm{CPB}$ to discern the impact of early versus late $\mathrm{CPB}$ on perioperative outcomes, including operative mortality and major morbidity. This was an elegant and sophisticated study in which the primary outcomes, the study design, and the statistical analysis were appropriate to the question. 
Within the high anatomic risk cohort, operative mortality was statistically similar for both early and late CPB groups. Likewise, operative mortality was comparable for each CPB group, within the low anatomic risk cohort. Unsurprisingly, there were more intraoperative blood product transfusions in the early CPB group (within both anatomic risk cohorts). Interestingly, however, there were more major re-entry injuries in the late CPB group of the low anatomic risk cohort, as compared with the early $\mathrm{CPB}$ group of the low anatomic risk cohort, whereas the incidence of major re-entry injuries was similar for each CPB group of the high anatomic risk cohort. Otherwise, major morbidity was similar for each CPB group (within each anatomic risk cohort), including new dialysis requirement, stroke, prolonged ventilation ( $>24$ hours), and re-exploration for excessive bleeding, to name a few. The authors are to be congratulated on their excellent outcomes in this redo cohort.

As the authors conclude, "surgeon experience and preference are important when there is no obvious a priori advantage for a given approach." However, the comparable results for early and late CPB (within each anatomic risk strata) suggest that there is no obvious a posteriori advantage either, which mitigates their claim that "patient-related anatomic and physiologic considerations are important in selecting a particular surgical approach." That is to say, does this study support the idea that preoperative riskstratification, as a driver of CPB timing, has an impact on outcomes? It would appear not. Once preoperative anatomic risk was determined, operative mortality was similar across cannulation strategy, potentially suggesting that early and late CPB appear to display clinical equipoise. More speculatively, one might further conclude that preoperative computed tomography-guided risk-stratification is potentially superfluous. However, the study was admittedly not designed to make that determination. To assess the impact of preoperative risk-stratification, the entire reoperative cohort needed to be analyzed as a whole, not separately analyzed by anatomic risk strata. An advantage of analyzing the population as a whole might have been the ability to assess any moderating interaction between preoperative anatomic risk and the timing of $\mathrm{CPB}$, as it relates to operative outcomes. This would have been justifiable, given the similar unadjusted operative mortality in each group (4.1\% for early $\mathrm{CPB}$ and $3.5 \%$ for late $\mathrm{CPB}$ ), although baseline differences would still necessitate a propensityweighted methodology.

It should be noted that the results may cut both ways because one might also conclude that concerns over early $\mathrm{CPB}$ are exaggerated. That is, while early CPB is associated with prolonged heparin exposure, excessive bleeding, and increased blood product transfusions, early CPB may be equally as safe as late CPB, ceteris paribus. However, despite statistical nonsignificance for operative mortality and major morbidity, we should note that the KaplanMeier estimates for long-term survival appear to separate over time for each CPB group, suggesting that early CPB may eventually display an adverse effect in the long run. ${ }^{10}$

While the data suggest clinical equipoise regarding CPB timing, it is possible that surgeon preference and expertise with late versus early CPB might primarily drive the low morbidity and mortality reported in this study. That is, operating surgeon may mediate the relationship between CPB timing and operative outcomes. In this study's design, while the definition of anatomic risk remained objective, the decision to initiate CPB before or after resternotomy was at the surgeon's discretion; hence, the discrepancy between the proportion of high and low risk patients in comparison with the proportion of early and late CPB patients. The critical implication of this fact is the importance of operating surgeon as a confounding factor. While adjusting for operating surgeon as a random effect enhances one's ability to evaluate the true effect of CPB timing, it only imperfectly overcomes the selection bias inherent in the comparator groups. Thus, despite adjustment, operating surgeon may still confound the influence of CPB timing, thereby harboring most of the explanatory power for predicting the outcomes in question. The reader should therefore be cautioned that, despite the sophisticated statistical methods, there may still be a real impact of CPB timing on operative mortality and major morbidity, and this effect may be either positive or negative. However, only a prospective trial could "prove" any causal relationship between CPB timing and outcomes.

Perhaps the most interesting finding is the increased rate of re-entry injury in the late $\mathrm{CPB}$ group of the low-risk cohort. To be sure, the clinical implications are unclear: despite those re-entry injuries, operative mortality appears to be unaffected in the low-risk cohort. The authors suggest that surgeon vigilance may be responsible for the comparable incidence of re-entry injury in the high-risk cohort, whereas the low-risk cohort may not have always received all of the appropriate preventive strategies during sternal reentry. This is very likely to be true. Finally, it should be noted that this study included a heterogenous mix of reoperations, including aorta and root operations in addition to coronary and valve operations. Moreover, each reoperation had a different tendency to undergo early versus late CPB; thus, future research might also investigate the impact of preoperative risk-stratification and CPB timing at the level of individual operations (eg, hemiarch replacement alone).

As Warren Buffett famously said, "risk comes from not knowing what you're doing." On one interpretation, this study suggests that the degree of risk inherent to resternotomy is partially driven by surgeon skill and expertise. Given their outstanding outcomes after reoperative cardiac surgery, the authors have demonstrated that they "know what they're doing." Having said that, the degree to which 
preoperative risk-stratification ought to dictate cannulation strategy for reoperative cardiac surgery remains unclear. It may be the case that early and late CPB are truly equivalent insofar as it reflects the preferences of the operating surgeon. However, only a direct comparison of each cannulation strategy in the setting of a prospective trial would be able to discern a real impact of CPB timing.

\section{References}

1. Roselli EE, Pettersson GB, Blackstone EH, Brizzio ME, Houghtaling PL, Hauck R, et al. Adverse events during reoperative cardiac surgery: frequency, characterization, and rescue. J Thorac Cardiovasc Surg. 2008;135:316-23.

2. Bianco V, Kilic A, Gleason TG, Aranda-Michel E, Habertheuer A, Wang Y, et al. Reoperative cardiac surgery is a risk factor for long-term mortality. Ann Thorac Surg. 2020;110:1235-42.

3. Kilic A, Acker MA, Gleason TG, Sultan I, Vemulapalli S, Thibault D, et al. Clinical outcomes of mitral valve reoperations in the United States: an analysis of the Society of Thoracic Surgeons national database. Ann Thorac Surg. 2019;107: 754-9.
4. Luciani N, Anselmi A, De Geest R, Martinelli L, Perisano M, Possati G. Extracorporeal circulation by peripheral cannulation before redo sternotomy: indications and results. J Thorac Cardiovasc Surg. 2008;136:572-7.

5. LaPar DJ, Ailawadi G, Harris DA, Hajzus VA, Lau CL, Kern JA, et al. A protocoldriven approach to cardiac reoperation reduces mortality and cardiac injury at the time of resternotomy. Ann Thorac Surg. 2013;96:865-70.

6. Kogon BE, Daniel W, Fay K, Book W. Is the liberal use of preoperative 3-dimensional imaging and presternotomy femoral cutdown beneficial in reoperative adult congenital heart surgery? J Thorac Cardiovasc Surg. 2014; 147:1799-804.

7. Kuralay E, Bolcal C, Cingoz F, Günay C, Yildirim V, Kilic S, et al. Cardiac reoperation by Carpentier bicaval femoral venous cannula: GATA experience. Ann Thorac Surg. 2004;77:977-81.

8. Imran Hamid U, Digney R, Soo L, Leung S, Graham AN. Incidence and outcome of re-entry injury in redo cardiac surgery: benefits of preoperative planning. Eur J Cardiothorac Surg. 2015;47:819-23.

9. Kindzelski BA, Bakaeen FG, Tong MZ, Roselli EE, Soltesz EG, Johnston DR, et al. Modern practice and outcomes of reoperative cardiac surgery. J Thorac Cardiovasc Surg. 2022;164:1755-66.e16.

10. Brown JA, Kilic A, Aranda-Michel E, Serna-Gallegos D, Habertheuer A, Bianco V, et al. The long-term impact of peripheral cannulation for redo cardiac surgery. J Card Surg. 2020;35:1920-6. 